\title{
Keçilerde Kazeöz Lenfadenitis (KLA) Hastalığına Bağlı Yüzlek Apse Sıklığının Değişimi
}

\author{
Cemil Tölü*, Türker Savaş \\ Çanakkale Onsekiz Mart Üniversitesi Ziraat Fakültesi Zootekni Bölümü, Terzioğlu Yerleşkesi, 17020-Çanakkale \\ *e-posta: cemiltolu@ comu.edu.tr; Tel: +90 (2286) 2180018 / 1326; Faks: +90 (286) 2180545
}

\begin{abstract}
Özet
Hayvan sağlığını olumsuz olarak etkileyen hastalıklar ekonomik açıdan önemli oldukları kadar, gıda güvenliği ve zoonozlar bakımından da önem arz ederler. Bu nedenle hayvan hastalıkları ile mücadelenin sistemli bir biçimde ele alınması, her aşamada kontrol ve risk noktalarının belirlenmesi gerekmektedir. Bu çalışmada, küçükbaş hayvanlarda yaygın olarak görülen Kazeöz Lenfadenitis (Pseudotuberculosis) hastalığına bağlı yüzlek apse sıklığının genotip ve mevsime göre değişimleri irdelenmiştir. Gökçeada, Malta ve Türk Saanen keçi genotiplerinde 2 yıl süreyle takip edilen yüzlek apselerin, \%15'i baş, \%32'si boyun, \%37'si sırt, \%14'ü bel ve \%2'si sağrı kısmında görülürken, tüm genotiplerde 1 yaşına kadar yüzlek apse tespit edilmemiştir. Yüzlek apse görülme oranı her iki yılda da genotip ve aylara göre önemli düzeyde farklılık göstermiştir $(P \leq 0.05)$. Her iki y1lda da Gökçeada genotipinde, Malta ve Türk Saanen genotipinden önemli düzeyde daha düşük oranda yüzlek apse olduğu belirlenmiştir $(P \leq 0.05)$. Gökçeada ve Malta keçilerinde apse sıklığı ikinci yılda biraz artış gösterirken, Türk Saanen genotipinde yıllar arasında bir farklılık oluşmamıştır. Yüzlek apse sıklığının ilkbahar ve yaz aylarında yüksek düzeylerde, kış aylarında ise düşük seviyelerde olduğu tespit edilmiştir $(P \leq 0.05)$. Hastalığın kontrolünde, geliştirilen aşıların dikkatle takip edilmesi ve uygulanması elzemdir. Ancak aşılamanın yanı sıra, işletmede dış parazit kontrolünün yıl boyu, özellikle ilkbahar ve yaz aylarında daha etkili yapılması, çiftlik alet ve ekipmanlarının deride yaralanma yapmamasına dikkat edilmelidir.
\end{abstract}

Anahtar kelimeler: Gökçeada, Malta, Türk Saanen, mevsim, dış parazit

\section{Variation in the Frequency of Superficial Abscesses based on the Caseous Lymphadenitis (CLA) Disease in Goats}

\begin{abstract}
The diseases which negatively affect animal health are as important in terms of food safety and zoonoses as they are economically. Therefore, animal disease control must be considered systematically and controlling and risk points must be determined at each stage. The variations in the frequency of superficial abscesses based on Pseudotuberculosis, widely seen in sheep/goats by genotype and season were investigated in this study. Of the superficial abscesses followed in the Gökçeada, Maltese, and Turkish Saanen goat genotypes for 2 years, $15 \%$ were detected in the head, $32 \%$ in the neck, $37 \%$ in the dorsum, $14 \%$ in the loin, and $2 \%$ in the rump. No superficial abscess was detected in the animals until 1 year of age. The incidence of superficial abscesses significantly varied by genotype and month in both years $(P \leq 0.05)$. It was determined that there was a significantly lower incidence of superficial abscesses in the Gökçeada genotype than in the Maltese and Turkish Saanen genotypes in both years $(P \leq 0.05)$. The frequency of abscesses slightly increased in the Gökçeada and Maltese goats in the second year, whereas there was no variation by year in the Turkish Saanen genotype. It was seen that the frequency of superficial abscesses was high in spring and summer months but low in winter months $(P \leq 0.05)$. It is indispensable to carefully follow and apply the developed vaccines in the control of the disease. However, besides vaccination, attention should be paid to the fact that ectoparasite control be carried out continuously on the farm, with it being performed seriously in spring and summer months in particular, and that the farm equipment and especially the points at which it touches the animal cause no injury on the skin.
\end{abstract}

Key words: Gökçeada, Maltese, Turkish Saanen, season, ectoparasite

\section{Giriș}

Günümüzde hayvan hastalıklarının kontrolünde bütüncül yaklaşımlar ön plana çıkmaktadır. Bu anlamda yetiştirme koşulları, genetik direnç, pasif ve aktif yollarla oluşan bağışıklık ve parazit kontrolü önemli rol oynamaktadır (Bath ve ark., 2005). Keçilerde tavsiye edilen sağlık koruma programları incelendiğinde, gözlem ve kayıt, besleme ve yemleme pratikleri, yıllık aşılama ve parazit mücadelesini içeren bir takvim ile hijyen konularına vurgu yapıldığı görülmektedir. Yanı sıra hayvanların fizyolojik dönemleri dikkate alınmakta ve bütün uygulamalar bu dönemler gözetilerek yürütülmektedir (Pennington, 2004; Bliss, 1992). 
Yetiştiriciler arasında "yalancı verem" "cırtlak" "çatlak" "apse" "çıban" olarak bilinen Pseudotuberculosis ya da diğer adı ile Kazeöz Lenfadenitis (KLA) çoğu evcil hayvanlar olmak üzere, koyun ve keçilerde çok sık görülmekte ve daha fazla ekonomik kayılara neden olmaktadır (Baird ve Fontaine, 2007; Windsor, 2011). Pseudotuberculosis, internal ve external formları olmak üzere, lenf yumrularında, akciğer ve diğer iç organlarda meydana gelen sarı-yeşilimsi irinli apseler ile karakterize olan, kronik ya da subakut seyreden, dünyada ve ülkemizde oldukça yaygın bulaşıcı bir hastalıktır ve son yıllarda görülme sıklığı sürekli olarak artmaktadır (Matthews, 1999; Baird ve Fontaine, 2007; Mohan ve ark., 2008). Zoonoz bir hastal1k olan Pseudotuberculosis'in apselerindeki irinler insanlara bulaşabildiği gibi et ve süt yoluyla da insanlara bulaşma riski bulunmaktadır (Bastos ve ark., 2012). Vücudunda bu hastalığı barındıran hayvanlarda etkenin önemli ölçüde (\%40) dolaylı yoldan solunum yolu hastalıklarına neden olduğu bildirilmektedir (Pratt ve ark., 2006). Hastalığın tipik belirtisi olan yüzlek apselerden büyük oranda Corynebacterium spp. türleri sorumlu tutulmaktadır (Chirino-Zarraga ve ark., 2006). Genellikle lenf yumrularında görülen apseler başta akciğer olmak üzere iç organlarda da görülebilirken, bu formların keçilerde koyunlara göre görülme olasılığı daha düşük düzeylerdedir (Matthews, 1999). KLA yüzlek formlarıyla deride ve yapağıda bozulmalara yol açarken, vücut üzerindeki ve iç organlardaki apseler canlı ağırlık artışını, karkas kalitesini ve verimliliği olumsuz yönde etkilemektedir (Gates ve ark., 1977; Paton ve ark., 1988). Koyunlarda özellikle iç organlardaki apseler nedeniyle kronik pnömoni ve hastalığa bağlı irinler ve ateşlenmeler "thin ewe syndrome" olarak adlandırılan görüntüye sebep olabilmektedir (Gates ve ark., 1977; Renshaw ve ark., 1979). Hastalıktan korunmada aşılama (İzgür ve ark., 2010), yaygın olmamakla beraber, hastalığın kontrolünde ve taşınmasında rol oynayan dış parazitlerin kontrolü, alet-ekipman dezenfeksiyonu, uygun bakım ve besleme de önemli rol oynamaktadır (Doherr ve ark., 1999; Daş, 2004).

Son yıllarda yapılan çalışmalar; hayvanlar arasında hastalıklara direnç veya tolerans anlamında önemli varyasyonların bulunduğu ve temelde arzulanan dirençli, dayanıklı veya toleransı yüksek hayvanların yetiştirilmesinin mümkün olabileceğini göstermektedir (Bishop ve Stear, 1997; Cardellino ve ark., 2002; Gauly ve Erhardt, 2002). Bu çalışmada yararlanılan keçi genotiplerinde hayvan başına sağlık uygulaması, oğlak ishalleri ve Ektima hastalıklarında genotipler arasında önemli farklıkların olduğu yapılan çalışmalarla ortaya konulmuştur (Tölü, 2009; Tölü ve ark., 2011). Pseudotuberculosis hastalığında koyun ve keçi türleri arasında farklılık olduğu gibi (Al-Gaabary ve ark., 2010; Al-Harbi, 2011), yüzlek apse sıklıklarının ırklara göre de önemli ölçüde değiştiği belirlenmiştir (Pepin ve ark., 1988; Al-Harbi, 2011). Y1l içerisinde apse sıklıklarında farklıklar olduğu görülürken, bu durumun dış parazit yoğunluğunun önemli bir etken olduğu belirtilmektedir (Doherr ve ark., 1999; İlhan, 2013). Ayrıca Pseudotuberculosis hastalığında dişi hayvanlarda erkek hayvanlara göre daha yaygın olduğu bildirilmiştir (Al-Gaabary ve ark., 2010).

$\mathrm{Bu}$ çalışmada, küçükbaş hayvanlarda yaygın olarak görülen ve Gökçeada, Malta (Maltız) ve Türk Saanen keçi genotiplerinde 2 yıl süreyle takip edilen Kazeöz Lenfadenitis hastalığına bağlı yüzlek apse sıklığının genotip ve mevsime göre değişimleri irdelenmiştir.

\section{Materyal ve Yöntem}

Çalışma, Ekim 2006-Aralık 2008 tarihleri arasında, Çanakkale Onsekiz Mart Üniversitesi Teknolojik ve Tarımsal Araştırmalar Merkezi (TETAM) Küçükbaş Hayvan Yetiştirme biriminde yarı-entansif sistemde yetiştirilen Gökçeada, Malta (Maltız) ve Türk Saanen keçi genotiplerinde yürütülmüştür. Çalışmanın hayvan materyalini, farklı yaşlardaki ergin dişi ve erkekler ile oğlaklar olmak üzere; Gökçeada genotipinde 145 baş, Malta genotipinde 172 baş ve Türk Saanen genotipinde 345 baş hayvanın kayıtlarından yararlanılmıştır. Gökçeada keçileri, Gökçeada'dan serbest sistemde yetiştirilmekte olan hayvanlardan, Malta keçileri ise Tekirdağ ili Malkara ilçesinin, Saanen melezlemesinin yapılmadığı köylerindeki farklı sürülerden temin edilmiştir. Ekim 2006'da birime getirilen genotipler bir ay süre ile karantina bölmelerinde tutulduktan sonra deneme ağıllarına alınmıştır. Türk Saanen genotipi ise 1995 yılında bu yana Çanakkale Onsekiz Mart Üniversitesi bünyesinde yetiştirilmektedir (Tölü, 2009).

Gökçeada, Malta ve Türk Saanen keçilerinde on beş günlük aralıklarla, canlı ağırlık tartımları sırasında her bir keçi elle muayene edilerek yüzlek apseler açısından kontrol edilmiştir. Bu amaçla hayvanın baş, boyun, sırt, bel ile sağrısında sağ-sol ve olgunluk derecesine göre görülen apseler kayıt edilmiştir (Daş ve ark., 2005). Ancak apse sıklığı düşük olduğundan vücudun bölgeleri ve apsenin olgunluk durumu göz önüne alınmaksızın, oluşturulan dönemlerde (aylar) apse görülme olasılığ1 şeklinde değerlendirilmiştir. Aylar hayvan başına sağlık uygulamasında olduğu gibi dört döneme ayrılmıştır. 
Elde edilen veriler yıl ve aylara göre hayvan başına görülme oranı (\%) şeklinde düzenlenmiştir. Bireysel sağlık uygulamasının analizi için yıl; 1. Dönem; Ocak, Şubat, Mart, (Doğum, Erken laktasyon), 2. Dönem; Nisan, Mayıs, Haziran, (Orta laktasyon, Mera ve İklim), 3. Dönem; Temmuz, Ağustos, Eylül (Aşım sezonu, Mera değişimi) ve 4. Dönem; Ekim, Kasım, Aralık (Laktasyon sonu, Gebelik) olmak üzere dört döneme ayrılmıştır. Sürüde Pseudotuberculosis hastalığına karşı aşılama (Glanvac ${ }^{\mathrm{TM}} 6 \mathrm{~S}$ ) yılda bir kez ilkbahar aylarında yapılmıştır (Tölü, 2009).

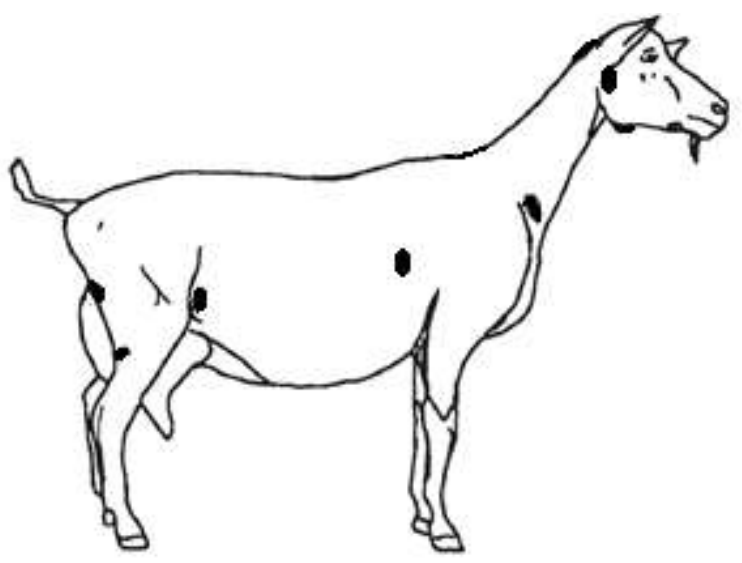

Şekil 1. Keçilerde Kazeöz Lenfadenitis (KLA) hastalığına bağlı lenf yumrularındaki apselerin (koyu siyah noktalar) vücutta görülme noktaları (Smith ve Sherman, 2009'dan değiştirilerek alınmıştır)

Elde edilen verilerin istatistiki analizleri, yılların ayrı ayrı değerlendirildiği tekrarlı ölçümler genelleştirilmiş eşitlik kestirimi (GEE) yöntemine göre yapılmıştır. Modelde genotip (Gökçeada, Malta, Türk Saanen) ve aylık dönemler $(1, \ldots, 4)$ yer almıştır. İkili karşılaştırmalarda WALD ki-kare testinden yararlanılmıştır (SAS, 1999).

\section{Bulgular ve Tartışma}

Çalışma öncesinde Türk Saanen sürüsünün KLA ile enfekte olduğu bilinirken, Gökçeada keçilerinde yüzlek apse gözlenmemiştir. Malta keçilerinde ise işletmeye getirildiklerinde sadece bir hayvanda apse tespit edilmiştir.

Keçilerde iki yıl süresince takip edilen KLA yüzlek apselerinin \%15'i baş (özellikle kulak altı), \%32'si boyun (özellikle boyun ile bacakların birleşme noktalarında), \%37'si sırt (özellikle göğüs kafesinin üzerinde), \%14'ü bel (özellikle arka bacak kürek kemiği ile vücudun birleştiği kavram noktasının üzerinde) ve $\% 2$ 'si sağrıda (özellikle bacak ve memeye doğru) tespit edilmiştir (Şekil 1). Çalışma süresince hayvanların vücutlarının başka noktalarında herhangi bir yüzlek apse görülmemiştir. Hayvanlarda 1 yaşına kadar yüzlek apse tespit edilmemiştir. Araştırma süresince, klinik olarak, KLA hastalığına bağlanabilecek ölüm görülmemiştir. Guimaraes ve ark., (2009), küçükbaş hayvanlarda yüzlek apselerin küçük yaşlarda oldukça düşük sıklıklarda olduğu ve yaşla birlikte arttığını belirtmişlerdir. Alloui (2011) keçi ve koyunlarda Pseudotuberculosis hastalığına ilişkin yaptı̆̆ çalışmada, 1 yaşın altındaki keçilerde prevalansı $\% 0$ bulurken, 1 yaşın altındaki koyunlarda $\% 0,8$ olarak bildirmiştir.

Çalışmada KLA yüzlek apselerinin en sık olarak göğüs kafesi üzerinde sırt bölgesinde ve boyunda olduğu tespit edilmiştir. Daş (2004), Türk Saanen genotipinde yaptığı çalışmasında, yüzlek apselerin \%67'sinin vücudun preskapula boyun kısmında olduğunu bildirmiştir. Yazar, ağıl donanımı ile en çok irtibatlı vücut bölümünün bu bölge olduğunu, dolayısıyla bu bölgede yaralanmaların diğer vücut bölümlerine göre daha fazla görülebileceğinden hareketle, boyun bölgesinin kontaminasyona diğer vücut bölümlerine nazaran daha açık olduğunu ifade etmektedir. Araştırmacının boyun için öngördüğü olumsuzluğun vücudun diğer bölgeleri için de geçerli olduğu söylenebilir.

Genotip ve dönemlere göre yıl içi hayvan başına yüzlek apse görülme olasıllı̆ Yüzlek apse görülme oranı her iki yılda da genotip ve dönemlere göre önemli düzeyde farklılık göstermiştir $(P=0.0179-P<0.0001)$. Her iki yılda da Gökçeada genotipinde Malta ve Türk Saanen genotipinden önemli düzeyde daha düşük oranda yüzlek apse olduğu belirlenmiştir ( $P \leq 0.05$; Çizelge 1). Gökçeada ve Malta keçilerinde apse sıklığı 2008 yılında biraz artış gösterirken, Türk Saanen genotipinde yıllar arasında bir farklılık oluşmamıştır. Cannor ve ark. (2000)'nın apselerin entansif sistemde daha yaygın olduğuna ilişkin bildirişleri, Gökçeada keçilerinde işletmeye getirildiklerinde apse görülmemesi ve Malta keçilerinin yalnızca birinde görülmesinin nedenini açılar niteliktedir. Araştırma başlangıcında genotiplere ilişkin KLA enfeksiyon düzeyi bilinmediğinden, apse sıklı̆̆ konusunda yalnızca genetik bir etkiden bahsetmek zor olsa da, gerek Gökçeada keçileri gerekse Malta keçileri, KLA apse sıklığı açısından deneme süresi boyunca Türk Saanenler ile aynı koşullarda yetiştirilmişlerdir. Nitekim her iki rrkta da enfeksiyon gelişmiştir. Türk Saanen keçilerinden dolayı kontamine bir çevrede yeni bir enfeksiyonun gelişmesinin daha şiddetli olması beklenir. Gökçeada ve Malta genotiplerinde apselerin 
Çizelge 1. Keçi genotiplerinde yıl ve dönemlere ait hayvan başına yüzlek apse görülme oranları (\%) ve önem seviyeleri

\begin{tabular}{lcccccccc}
\hline \multirow{2}{*}{$\begin{array}{l}\text { Genotip } \\
\text { Dönemler }\end{array}$} & \multicolumn{2}{c}{ Gökçeada } & \multicolumn{2}{c}{ Malta } & \multicolumn{2}{c}{ Türk Saanen } & \multicolumn{2}{c}{ Genel } \\
\hline 1 & 2007 & 2008 & 2007 & 2008 & 2007 & 2008 & 2007 & 2008 \\
2 & 0.0 & 4 & 0.0 & 7.5 & 0.0 & 14.9 & $0.0^{\mathrm{a}}$ & $8.8^{\mathrm{x}}$ \\
3 & 2.7 & 2.3 & 12.8 & 12.2 & 17 & 11.9 & $10.8^{\mathrm{b}}$ & $8.8^{\mathrm{x}}$ \\
4 & 4.5 & 5.2 & 15.3 & 8.8 & 19.7 & 16.9 & $13.1^{\mathrm{b}}$ & $10.3^{\mathrm{x}}$ \\
\hline Genel & 0.0 & 0.0 & 3.7 & 4.6 & 11.7 & 4.9 & $5.1^{\mathrm{c}}$ & $3.1^{\mathrm{y}}$ \\
\hline
\end{tabular}

1. Dönem; Ocak, Şubat, Mart, (Doğum, Erken laktasyon), 2. Dönem; Nisan, Mayıs, Haziran, (orta laktasyon, Mera, İklim), 3. Dönem; Temmuz, Ağustos, Eylül (Aşım sezonu, Mera değişimi) ve 4. Dönem; Ekim, Kasım, Aralık (Laktasyon sonu, Gebelik); 2007 (a-c) ve 2008 (x-y) yıllarında genotip ve dönemler içerisinde farklı küçük harflerle gösterilen ortalamalar arasındaki fark istatistiksel olarak önemlidir $(P \leq 0.05)$.

daha sık olması beklenirken, bulgular bunun tersini göstermektedir. Bu nedenle, her ne kadar Gökçeada ve Malta genotipleri işletmeye ilk getirildiklerindeki bunlardaki apse sıklığının Türk Saanen keçilerine göre düşüklüğü yetiştirme sistemi farklılığı ile açıklansa da, takip eden iki yıl boyunca genotipler aynı sistemde yetiştirilmişlerdir. Dolayısıyla genotipler açısından Pseudotuberculosis apse sıklığında oluşan farklıkların en azından bir kısmının genetik kaynaklı olabileceği söylenebilir.

Yüzlek apse sıklıklarının yıllar içerisinde dönemlere göre önemli ölçüde değiştiği görülmüştür $(P \leq 0.05$; Çizelge 1). Yüzlek apse sıklığının genellikle 2. dönemde yükselişe geçtiği, en yüksek sıklığa 3 . dönemde ulaştığı görülmektedir. 2008 yılında sonbahar dönemi olan 4. Dönemde düşük apse sıklığı ile diğer dönemlerden önemli ölçüde farklılaşırken, 2007 yılında ilkbahar ve yaz aylarına denk gelen 2. ve 3. Dönemler dışında diğer dönemlerin apse sıklığı oranlarının önemli ölçüde farklılaştığı dikkati çekmiştir $(P \leq 0.05)$. İlkbahar ve yazlarına denk gelen 2 . ve 3 . Dönemlerin ise her iki yılda da apse sıklıklarının önemli ölçüde farklılaşmadığı görülmüştür $(P \geq 0.05)$. Doherr ve ark. (1998) atlarda yaptıkları çalışmada, mevsimlerin apse sıklıklarını önemli ölçüde etkilediğini, yaz ve sonbahar aylarında apse sıklığı ve klinik müdahalelerin arttığını belirlemişlerdir. Çalışmada Nisan-Eylül ayları arasında apse sıklığının artışı taşıyıcı muhtemel dış parazitlerin bu dönemlerde yoğunlaşmasından kaynaklanabilir. Ayrıca keçilerin 1. Dönemde uzamış kıllarını bu aylarda dökmeye başlaması ve özellikle sineklerin deride daha fazla tahriş yaptığı da göz önünde tutulmalıdır. Pepin ve ark. (1991), kuzularda yaptıkları çalışmada, Pseudotuberculosis hastalığ 1 etkeninin deriden girdikten 24 saat sonrasında lenf dügüumlerinde küçük apselerin şekillenmeye başladığını bildirmişlerdir.

\section{Sonuç ve Öneriler}

Keçilerde iki yıl süresince takip edilen KLA yüzlek apselerinin büyük bir kısmının göğüs kafesinin dorsali ve boyun ile göğüsün birleşme noktasına yakın boyun bölgesinde sıklaştığı görülmüştür. Enjektörle yapılan aşılamaların daha ziyade sırta yapılması, boynun ise keçilerin yemleme ve sağım ünitesinde metal aksamla temas noktası olması ile deride oluşan açılmalar nedeniyle kontaminasyona daha yatkın olduğu ifade edilebilir. Genotipler arasında KLA apse sıklığı bakımından çalışma başlangıcında oluşan fark her ne kadar geçmişlerindeki yetiştirilme koşullarından kaynaklanıyor olduğu düşünülüyorsa da, sonraki süreçte tüm genotiplerin aynı koşullarda yetiştiriliyor olmaları ve ortamın da KLA etmenlerince kontamine olduğu biliniyor olmasından hareketle, genotipler arasındaki farkın bir kısmının genetik kaynaklı olduğu söylenebilir. Ancak hangi mekanizmaların etkili olabileceği konusunda daha fazla fikir yürütmek bu çalışmanın bulgularıyla mümkün değildir. Örneğin, Gökçeada genotipler içinde en uzun kıl örtüsüne sahip iken, Türk Saanen en kisa k1l örtüsüne sahiptir. Bu durum, kısa k1l örtüsüne sahip genotiplerin kontaminasyona daha yatkın olabileceği şeklinde speküle edilebilir.

Hastalığın etmeni solunum ve sindirim yoluyla bulaşabilirken, etken özellikle açılan deriden yayılmaktadır. Muhtemelen apse sıklığı, KLA etmeninin, özellikle deride oluşan irritasyon, dermatit ve yaralardan girerek apse oluşturması nedeniyle, özellikle dış parazitlerin çoğaldığı Nisan-Eylül gibi ilkbahar ve yazaylarında artmaktadır. Kış aylarında ise $\mathrm{d}_{1}$ ş parazitlerin ve özellikle sineklerin azaldığı gibi, deride irritasyon ve dermatit olasılığı da düşerek apse sıklıkları en düşük seviyeye inmektedir.

Bulgular yılın sıcak döneminde hastalık açısından daha bir hassas olunması gerektiğine işaret etmektedir. 
İşletmede dış parazit ve özellikle sinek kontrolüne özellikle ilkbahar ve yaz aylarında gerekli hassasiyetin gösterilmesi ve hayvanlarıntemas ettikleribarınak yapıları ile ekipmanlar konusunda önlem alınması gerekmektedir. Ayrıca hayvanlardaki yüzlek apseler olgunlaştığında, apsenin açılması, temizlenmesi ve antiseptik solüsyonla dikkatlice yıkanması sırasında çevrenin kontamine olmaması için hijyen kurallarına uyularak etmenin işletmede yayılması önlenmelidir.

\section{Teşekkür}

Yazarlar, bir proje kapsamında (106O411) Gökçeada ve Malta keçilerinin temin edilmesini destekleyen TÜBITTAK'a, canlı ağırlık tartımlarında yardımlarını esirgemeyen Dr. Hande Işıl AKBAĞ, hayvan bakıcıları Barış SUNAR, İzzet Erdal MANGIR'a teşekkür ederler.

\section{Kaynaklar}

Al-Gaabary, M.H., Osman, S.A., Ahmed, M.S., Oreiby, A.F. 2010. Abattoir survey on caseous lymphadenitis in sheep and goats in Tanta, Egypt. Small Rumin. Res. 94: 117-124.

Al-Harbi, K.B. 2011. Prevalence and etiology of abscess disease of sheep and goats at Qassim Region, Saudi Arabia. Vet. World 4(11): 495-499.

Alloui, M.N. 2011. Prevalence and risk factors of Caseous Lymphadenitis in sheep and goats of Batna Area (Algeria). Anim. Vet. Sci. J. 1(3): 162-164.

Baird, G.J., Fontaine, M.C. 2007. Corynebacterium pseudotuberculosis and its role in ovine Caseous Lymphadenitis. J. Comp. Path. 137: 179-210.

Bastos, B.L., Portela, R.W.D., Dorella, F.A., Riberio, D., Seyffert, N., Castrao, T.L.de P., Miyoshi, A., Oliveria, S.C., Meyer, R., Azevedo, V. 2012. Corynebacterium pseudotuberculosis: Immunological responses in animal models and zoonotic potential. J.Clin. Cell Immunol. S4: 1-15.

Bath, G.F., Van Wyk, J.A., Pettey, K.P. 2005. Control measures for some important and unusual goat diseases in southern Africa. Small Rumin. Res. 60: 127-140.

Bishop, S.C., Stear, M.J. 1997. Modelling responses to selection for resistance to gasto-intestinal parasites in sheep. Anim. Sci. 64: 469-478.

Bliss, E.L. 1992. Herd health program. Extension Goat Handbook, Health and Disease Management. Pennsylvania State University, U.S.A.

Cannor, K.M., Quire, M.M., Baird, G., Donachie, W. 2000. Characterization of United Kingdom isolates of Corynebacterium pseudotuberculosis using pulsed-field gel electrophoresis. J. Clin. Microbiol. 38: 2633-2637.

Cardellino, R.A., Nari, A., Castells, D. 2002. Animal health links to recording systems. Resistance to internal parasites in sheep. ICAR Technical Series No: 8p. 129-141.

Chirino-Zarraga, C., Scaramelli, A., Rey-Valeiron, C. 2006. Bacteriological characterization of Corynebacterium pseudotuberculosis in Venezuelan goat flocks. Small Rumin. Res. 65: 170-175.

Daş, G. 2004. Keçilerde sürü sağlığındaki yıllık değişimin bazı pratik parametrelerle izlenmesi (Yüksek Lisans Tezi). Çanakkale Onsekiz Mart Üniv., Fen Bilimleri Enst., Zootekni Anabilim Dalı, Çanakkale.

Daş, G., Savaş, T., Uzatıı, A. 2005. Bir süt keçisi sürüsünde yüzlek apseler üzerine gözlemler. Süt Keçiciliği Ulusal Kongresi, 26-27 Mayıs, İzmir.

Doherr, M.G., Carpenter, T.E., Hnason, K.M.P., Wilson, W.D., Gardner, I.A. 1998. Risk factors associated with Corynebacterium pseudotuberculosis infection in California horses. Prev. Vet. Med. 35: 229-239.

Doherr, M.G., Carpenter, T.E., Wilson, W.D., Gardner, I.A. 1999. Evaluation of temporal and spatial clustering of horses with Corynebacterium pseudotuberculosis infection. American J. Vet. Res. 60(3): 284-291.

Gates, N.L., Everson, D.O., Hulet, C.V. 1977. Effects of thin ewe syndrome on reproductive efficiency. J Am. Vet. Med. Assoc. 171(12): 1266-1267.

Gauly, M., Erhardt, G. 2002. Changes in feacal trichostrongyle egg count and haematocrit in naturally infected Rhön sheep over two grazing periods and associations with biochemical polymorphisms. Small Rumin. Res. 44: 103-108.

Guimaraes, A.S., Seyffert, N., Bastos, B.L., Portela, R.W.D., Myer, R., Carmo, F.B., Cruz, J.C.M., Mc Culloch, J.A., Lage, A.P., Heinemann, M.B., Miyoshi, A., Azevedo, V., Gouveia, A.M.G. 2009. Caseous lymphadenitis in sheep flocks of the state of Minas Gerais, Brazil: Prevalence and management surveys. Small Rumin. Res. 87: 86-91.

İlhan, Z. 2013. Detection of Corynebacterium pseudotuberculosis from sheep lymphnodes by PCR. Revue Med. Vet. 164(2): 60-66.

İzgür, M., Akan, M., İlhan, Z., Yazıcıoğlu, N. 2010. Studies on vaccine development for ovine caseous lymphadenitis. Ankara Üniv. Vet. Fak. Derg. 57: 161-165.

Matthews, J. 1999. Diseases of the goat. 2nd Edition. Blackwell Science, Inc., Madlen, MA, U.S.A., p. 124-126.

Mohan, P., Vathsala, M., Jayaprakasan, V. 2008. Comparative characterization of Corynebacterium pseudotuberculosis from goats in Kerala, India and reference strain. Small Rumin. Res. 74: 226-230. 
Paton, M.W., Mercy, A.R., Sutherland, S.S., Ellis, T.M. 1988. The influence of shearing and age on the incidence of caseous lymphadenitis in Australian sheep flocks. Acta Vet. Scand. 84: 101-103.

Pennington J.A. 2004. Herd Health Program for Dairy Goatsin Cooperation with the U.S. Department of Agriculture, Director, Cooperative Extension Service, University of Arkansas.

Pepin, M., Pardon, P., Marly, J., Lantier, F. 1988. Corynebacterium pseudotuberculosis infection in adult ewes by inoculation in the externalear. Am. J. Vet. Res. 49(4): 459-63.

Pepin, M., Fontaine, J.J., Pardon, P., Marly, J., Parodi, A.L. 1991. Histopathology of the early phase during experimental Corynebacterium pseudotuberculosis infection in lambs. Vet. Microbiol. 29,123-134.

Pratt, S.M., Spier, S.J., Vaughan, B., Withcomb, M.B., Uerling, M.R., Wilson, W.D. 2006. Respiratory disease caused by Corynebacterium pseudotuberculosis. Clin. Tech. Equne Pract. 5(3): 239-246.
Renshaw, H.W., Graff, V.P., Gates, N.L. 1979. Visceral caseous lymphadenitis in thin ewe syndrome: isolation of Corynebacterium, Staphylococcus, and Moraxella spp. from internal abscesses in emaciated ewes. Am. J. Vet. Res. 40(8): 1110-1114.

SAS, 1999. Institute Inc., SAS OnlineDoc ${ }^{\circledR}$, Version 8, Cary, NC.

Smith, M.C., Sherman, D.M. 2009. Goat Medicine, Second Edition, ISBN: 978-0-7817-9643-9, WileyBlackwell, Hong Kong. p. 63.

Tölü, C. 2009. Farklı keçi genotiplerinde davranış, sağlık ve performans özellikleri üzerine araştırmalar (Doktora tezi). Çanakkale Onsekiz Mart Üniv., Fen Bilimleri Enst., Zootekni Anabilim Dalı, Çanakkale, $204 \mathrm{~s}$.

Tölü, C., Topaloğlu, N., Savaş, T. 2011. Gökçeada, Malta ve Türk Saanen çebiçlerinde ağır bir ektima (Ecthyma contagiosum) olgusu üzerine gözlemler. Hayvansal Üretim 52(1): 39-43.

Windsor, P.A. 2011. Control of Caseous Lymphadenitis. Vet. Clin. Food. Anim. 27: 193-202. 